\title{
Casamento e família: por uma perspectiva interdisciplinar
}

\section{Cristiane Cecchin}

Universidade Federal de Santa Catarina (UFSC)

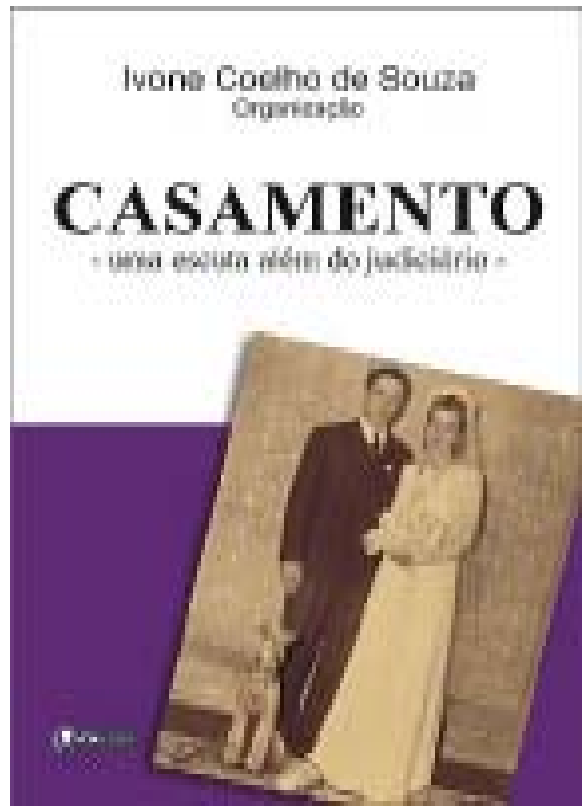

RESENHA: Casamento e família: por uma perspectiva interdisciplinar

SOUZA, Ivone M. C. Coelho de. [Org.]. Casamento: uma escuta além do judiciário. Florianópolis: VoxLegem, 2006. 544 p.

BOOK REVIEW: Marriage and Family: for an Interdisciplinary Perspective

SOUZA, Ivone M. C. Coelho de. [Org.]. Marriage: a Hearing Beyond the Judiciary. Florianópolis: VoxLegem, 2006. 544 p. 
Emerge um momento de difusão e crescimento nos campos de pesquisa que englobam estudos referentes à família no Brasil. Nos últimos anos, os passos trilhados para a direção do questionamento e da compreensão desta "instituição" demonstram que, simultaneamente à amplificação das produções e dos envolvimentos com o tema, afloram aprimoramentos e complexificações nas capacidades argumentativas e reflexivas dos pesquisadores, que atentam para uma caminhada cada vez mais densa e variada nos sentidos aos quais induzem suas atribuições.

Diante deste contexto, compreende-se a proposta de uma organização transdisciplinar dos debates referidos ao casamento naturalizado como a formalização legal e institucional da família contemporânea pelo discurso judiciário. Ao fomentar a idéia de uma necessidade eminente da transitoriedade entre os diferentes campos do saber relativos à família, a psicóloga Ivone M. C. Coelho de Souza sustenta sua inclinação em oxigenar as discussões lançadas pelo discurso jurídico no intento de definir as compreensões conceituais do casamento e seus desdobramentos (im)postos pelo Direito de Família na sociedade brasileira. Segundo a co-autora e organizadora da obra, as proposições conceituais implementadas pelo aparelho legislativo nas definições da compreensão das imagens de família no Brasil, não são por si só suficientes no atendimento das realidades que necessitam de tutela e apoio do Direito nas resoluções legais das querelas familiares postas em foco no cenário jurídico atual. Na concepção de Souza, é indispensável que os operadores do Direito em sua totalidade exercitem a transição dos debates, dos conceitos, das apreciações e diagnósticos estabelecidos em qualquer caso na perspectiva da interdisciplinaridade pela criação ou aplicação efetivas de seus processos no cotidiano.

Como especialista em Psicologia Clínica e Jurídica, pela convivência habitual com as operações jurídicas transversalizadas pelas exigências psicológicas nos casos sucessivos em que se envolve, fica evidente sua disposição em reunir primordial e enfaticamente um numeral extenso e diverso de juristas e psicólogos engajados na tarefa de encadear as discussões proponentes destes vínculos tão necessários à jurisdição neste ramo do direito. Para que seja evitada e mesmo cessada a marginalização das famílias envolvidas pela visão tecnicista e mecânica dos operadores em ação, aconselha verificar-se como essencial sua consideração como sujeitos jurídicos, na medida em que interpretam a lei - tratando das questões que possam evidenciar sua real necessidade - e não somente a aplicam de forma redutora e evasiva. A busca pelo equilíbrio entre a razão e a sensibilidade no Direito de Família é, portanto, a inquirição primordial da psicóloga sulriogradense na compilação destes trabalhos diversos, que têm por função angariar o reconhecimento dos valores da família como pautados pela coexistência entre as decisões externas da legislação e os conflitos e sensibilidades internas.

Neste cenário em que impera a força das decisões externas na dissolução das agitações internas, Souza tenciona as transformações da legislação e seus conceitos reinterpretados e recriados frente às modificações intensas pelas quais atravessa a realidade da família contemporânea na sociedade brasileira. Tais alterações, além de convirem para as exigências do contato entre estudos psicológicos e jurídicos, contribuem também para a percepção do texto jurídico como integrante das construções históricas sendo "indicativos robustos de que a família, como instituição dinâmica, efetivamente está em mudança".

Deste modo, a formalização do casamento como instância oficializante da "instituição" matrimônio pelo conceito judiciário - no ritual da burocratização da união como forma legítima de reconhecimento social do casal -, obriga-se a transfigurar seus desdobramentos voltados à consideração e apreciação das diversas formas de arranjo familiar que abarcam a família "póscontemporânea" no Brasil. Tal situação gera polêmicas e desconfortos no seio dos debates que se prestam à análise destas transformações. Os pareceres dos estudiosos dispostos no corpo da obra se investem desde ponderações sobre as necessidades inovadoras e flexibilizadoras da sociedade atual - na qual o texto jurídico seria elemento modificável e acompanhanteaté em juízos sobre a ideia de uma crise diante da dissolução dos limites que compunham as bases da família pela oficialização do casamento como institucionalização do matrimônio.

Por entre os artigos que compõem a coletânea, é sentida uma ausência de diálogos mais abrangentes com áreas que possam discutir o texto e a linguagem jurídica como criação e construção dos julgamentos que nos parecem em um olhar mais superficial, tão facilmente naturais e perenes. Num caminho em que se complexificam e aprofundam as argumentações no assunto, saltam as tendências a uma desnaturalização de conceitos, que, ao serem questionados, passam da condição cômoda e atemporal de "naturais" para a de socialmente construídos e naturalizados. Assim é que se fundam as proposições das pesquisas pelas inovações incômodas e inquietantes de campos de estudos como a História, a Antropologia Social e Cultural, a Sociologia, entre outras áreas dos estudos sociais, presentes em vários autores.

Na composição dos trabalhos distribuídos na obra, é possível perceber a escassez de profissionais ligados à esfera dos estudos da família pelo desenvolvimento acadêmico das Ciências Humanas. Entre os artigos, encontram-se somente os escritos por uma historiadora e uma antropóloga voltados para a discussão da invenção, criação e construção dos concei- 
tos sociais e jurídicos, assim como das imagens de família, relações de gênero e diferenciação de posturas no corpo da linguagem judiciária e seus interstícios culturais. Tal situação pode evidenciar uma forte resistência destas produções em conviver e estabelecer contatos com áreas que fujam aos ensaios "primordiais" dos profissionais considerados mais capacitados para tal função: todo o ramo de juristas e psicólogos dispostos às considerações e resoluções das questões referentes ao universo familiar e seus adendos.

Ao questionar as transformações das linhas delimitadoras da família - percebidas como sinais dos tempos ou exemplo de crises e dissoluções pela Psicologia e pelo Direito -, busca-se a compreensão de um denso processo presente na sociedade em suas construções culturais. A desagregação das linhas formais do casamento jurídico, seguida do avultamento e crescimento nas direções centradas pela união estável, como exemplo, não podem ser interpretadas somente como tendências e transformações contemporâneas demarcadas pelo corpo social "modificado" aos olhos do judiciário: a sociedade burguesa da família tradicional. As direções da família perdem concretude e segurança quando admitimos as disparidades de disposição e adesão aos apelos parentais propostos por uma "norma familiar burguesa" que se almeja homogeneizadora. Isto, sobretudo frente às conclusões da diversidade disposta nos arranjos familiares predominantes nos grupos populares, organizados numa lógica diferenciada da classe média, simultaneamente ao projeto de introdução da norma a todas as esferas da sociedade, primordialmente no decorrer do século 20. O que se deve alvitrar, para tal compreensão das diferenças na composição familiar da sociedade em suas diversas e múltiplas esferas, são as condições e as propensões que contêm cada particularidade social em suas atribuições singulares. Dessa forma, é possível notar que as variações ocorridas no âmago das relações familiares hoje passam longe da definição de crise ou inovação pós-contemporânea, posto que são mais remotas e menos lineares ou sucessivas do que nos parece a um primeiro momento de observação menos intensa.

Se hoje vivemos um momento de crítica explícita ao padrão de família burguesa relativo à consistência e manutenção dos desígnios da coletividade, pelo avultamento das motivações individualistas e supressão do imaginário do grupo (nós) ao do indivíduo (eu), são sem dúvida as objetivações pós-contemporâneas que dão o mote às necessidades e aos anseios de uma época inovadora disposta a rever suas considerações. No entanto, é equivocado reduzir estas disparidades à classificação pura de inovação e transgressão de conceitos considerados como modelos fundamentais do imaginário de família de que se dispõe recentemente, como se estes sempre existissem e fossem inertes à naturalização das representações sociais.

Nesse contexto, é inevitável notar que apesar das tendências aos caminhos individualistas que permeiam as discussões sobre a dissolução das bases da "família fundamental", esta ainda persiste no imaginário social em suas mais diversas formas e conformações nos arranjos propostos em cada situação. Ainda é corrente que a felicidade seja almejada nos laços da união conjugal, na concretização do amor romântico, na satisfação dos desejos pessoais pela convivência e contato com o parceiro desejado e amado; mesmo que os objetivos coletivos e sociais sejam subjugados à busca pela felicidade individual. E diante desta necessidade da família avistada principalmente pela circulação de publicações como esta, fica a indagação final posta a questionar ainda mais as linhas do que se discute neste tema. Como exemplo a ser seguido nos desígnios culturais da sociedade em que vivemos, quais são hoje as motivações da constituição da família contemporânea? As individuais, pautadas no sentimento particular de cada anseio pela felicidade romântica; ou as sociais, baseadas nas construções coletivas e no imaginário das reverberações da família?

\section{Cristiane Cecchin}

Mestranda em História pelo Programa de Pós-Graduação em História (PPGH)

Universidade Federal de Santa Catarina (UFSC). Orientadora: Profa. Dra. Maria Bernardete Ramos Flores

\section{UFSC}

Campus Universitário Reitor João David Ferreira Lima

Bairro Trindade

Florianópolis - Santa Catarina

Brasil 